\title{
Effect of health status evaluated at arrival on growth in milk-fed veal calves: A prospective single cohort study
}

\author{
D. L. Renaud, ${ }^{, 1}$ M. W. Overton,† D. F. Kelton, ${ }^{\star}$ S. J. LeBlanc, ${ }^{*}$ K. C. Dhuyvetter, $†$ and T. F. Duffield ${ }^{*}$ \\ *Department of Population Medicine, University of Guelph, Guelph, ON, Canada N1G 2W1 \\ †Elanco Animal Health, Greenfield, IN 46140
}

\begin{abstract}
The objective of this prospective single cohort study was to determine the effect of health status at arrival on growth in milk-fed veal calves. Upon arrival at the veal facility, calves were evaluated using a standardized health scoring system and weighed, and the supplier of the calf was recorded. The calves were followed until slaughter, when the hot carcass weight (HCW) was reported. To calculate average daily gain (ADG), the $\mathrm{HCW}$ was transformed into an estimated live weight, weight at arrival was subtracted, and this value was divided by the number of days on feed. A mixed linear regression model was created to evaluate the association of health status on arrival with the ADG throughout the production period. A total of 4,825 calves were evaluated at arrival; however, due to inconsistent HCW data from one slaughter plant, and 357 calves dying during the production period, 2,283 calves were used for analysis. In the final model, 7 variables were significantly associated with ADG. Housing location within the farm, method of calf procurement (drover or auction-derived calves versus direct delivery from local farms) and having a higher body weight at arrival were associated with a higher ADG. The season of arrival (summer or fall compared with winter) and being dehydrated at arrival were associated with a lower ADG. Days on feed was also significant in the multivariable model and had a quadratic relationship with ADG. The associations identified suggest that there may be value in scoring dehydration and body weight at arrival to a veal facility.
\end{abstract}

Key words: veal calf, growth, health status at arrival

\section{INTRODUCTION}

The veal industry operates under the premise of taking male dairy calves of low economic value and creating

Received April 20, 2018.

Accepted June 30, 2018

${ }^{1}$ Corresponding author: renaudd@uoguelph.ca a higher-value product - red meat. With the majority of pregnancies in the dairy industry resulting from the use of conventional semen (De Vries et al., 2008), there continue to be a large number of male calves produced by the dairy industry each year. In Canada, the majority of male calves in Ontario and Quebec enter the veal industry, as these provinces are the largest producers of veal, producing over 200,000 slaughtered animals in 2015 (Agriculture and Agri-Food Canada, 2016). Despite the large number of veal calves produced, little is known about their growth performance.

There is clear evidence in female dairy calves that disease affects growth and risk of culling before the first lactation (Virtala et al., 1996; Stanton et al., 2012; Windeyer et al., 2014). Pardon et al. (2013) demonstrated that a similar relationship existed with veal calves in Belgium, where calves with bovine respiratory disease (BRD) or diarrhea had reductions of 8 and $9 \mathrm{~kg}$, respectively, in hot carcass weight at slaughter. However, what remains unclear from the available literature is the effect that health status on arrival at the veal facility may have on calf performance.

Many calves enter the veal industry with health abnormalities (Bähler et al., 2012; Pempek et al., 2017; Renaud et al., 2018), some of which are associated with a greater risk of mortality (Renaud et al., 2018). Thus, establishing that initial health status affects growth would emphasize the need to selectively treat these calves at arrival and, more importantly, to prevent these conditions before arrival at the veal facility. The objective of this prospective single cohort study was to determine the impact of health status at arrival on growth in milk-fed veal calves.

\section{MATERIALS AND METHODS}

This prospective observational single cohort study was conducted in collaboration with a milk-fed veal producer located in southwestern Ontario, Canada. The producer had 5 barns in different geographical locations. In barns 1, 2, and 4, the calves were fed manually, whereas in barns 3 and 5, automatic calf feeders 
were used. Calves were housed individually in barns 1 and 4 and in groups of 60 calves in barns 3 and 5 . Calves in barn 2 were housed in individual pens in early life, transitioning to groups of 8 calves 5 to 6 wk after arrival. A standardized feeding schedule was used at all of the barns in this study, where initially the calves were provided $600 \mathrm{~g} / \mathrm{d}$ of $19 \%$ fat and $21 \%$ protein milk replacer and were eventually fed a maximum of 3,300 $\mathrm{g} / \mathrm{d}$ of $19 \%$ fat and $19 \%$ protein milk replacer. The detailed feeding schedule, including the rate of the increase in milk replacer by day, was not made available for publication by the facility owner. The study was completed in accordance with the University of Guelph Animal Care Committee requirements (Animal Use Protocol: \#3453).

\section{Data Collection}

When calves arrived at the barns, they were immediately evaluated using a standardized health scoring system and weighed using a digital scale (Cardinal Scale Manufacturing Co., Webb City, MO). The health scoring system guided the user to evaluate the respiratory system (nose, eye, ear, cough; McGuirk and Peek, 2014), fecal consistency (McGuirk, 2008), navel inflammation (adapted from Fecteau et al., 1997), joint swelling, and rectal temperature. The level of dehydration (adapted from Wilson et al., 2000), BCS (Wilson et al., 2000), and sunken flank (Bähler et al., 2012) were also evaluated and recorded. All calves were examined by 1 of 3 observers. Observer 1, a veterinary practitioner, provided training to observers 2 and 3 , who were veterinary students. The inter- and intra-observer agreement were calculated for observers 1 and 2 using weighted kappa $(\kappa)$. Observer 3 relocated to pursue another position and could not be assessed for observer agreement. The agreement ranged from almost perfect agreement to poor agreement (weighted $\kappa 0$ to 1 ; Renaud et al., 2018).

The supplier of the calf and receiving date were recorded. In total, there were 233 different recorded suppliers. These suppliers were divided into 7 categories (local, drovers, and auction). "Local" refers to dairy farmers who delivered their calves directly to the veal facility; 37 local farms were included in this category. The term "drover" was used for calves that were transported directly from multiple dairy farms to the veal facility by an identified third party; 5 drovers transported calves to this facility. "Auction" was used to classify calves purchased by the veal farm from 3 auction markets. Season was categorized as winter (December to February), spring (March to May), summer (June to August), and fall (September to November). Calves were identified at arrival based on their Canadian
Cattle Identification Agency (CCIA) ear tag. Trax-IT software (Merit-Trax Technologies; Mount Royal, QC, Canada) was used to record all mortalities occurring during the production period. Based on the CCIA ear tag, information regarding the number of days on feed and hot carcass weight (HCW) from the slaughter plant were also recorded.

\section{Sample Size Calculation}

A 2-sample means test was used to calculate the required sample size. It was estimated that a calf identified with a health abnormality at arrival would have an ADG of $1.47 \mathrm{~kg} / \mathrm{d}$ (SD: $0.26 \mathrm{~kg} / \mathrm{d}$ ), whereas a calf without an abnormality would have an ADG of 1.51 $\mathrm{kg} / \mathrm{d}$ (SD: $0.29 \mathrm{~kg} / \mathrm{d}$ ) (Pardon et al., 2013). Using 95\% CI and $80 \%$ power, a sample size of 1,007 calves per group was required.

\section{Statistical Analysis}

All statistical analyses were completed using Stata 14 (StataCorp LP, College Station, TX). Data were imported from Excel (Microsoft Corp., Redmond, WA) into Stata 14 and checked for completeness. Calves with missing data were deleted from analysis (complete-case analysis; Pigott, 2001). A causal diagram (Figure 1) was created to illustrate the hypothesized relationship between the dependent and independent variables, and was used to guide the analyses. Descriptive statistics were generated for all explanatory variables in the data set. Chi-squared tests for categorical variables and $t$ tests for continuous variables were conducted to ensure that the prevalence of the health abnormalities and weight measured at arrival were similar between the calves sent to an excluded slaughter plant and those sent to the plants retained in the analysis.

A mixed linear regression model was built to assess the association of health status measured at arrival with the growth of the calves. Average daily gain was calculated by using $\mathrm{HCW}$ to estimate final live weight, with the assumption that $\mathrm{HCW}$ was $58.5 \%$ of live weight at slaughter. This assumption was made based on previous data from this facility (Pascal Bouilly, University of Guelph, Guelph, ON, Canada; personal communication). The weight at arrival was subtracted from the estimated live weight at slaughter and this value was divided by the number of days on feed to produce the ADG for the growing period. The assumption of linearity of continuous variables was assessed by plotting ADG against the variable. If a variable failed to meet the linearity assumption, the variable was categorized. Collinearity among the explanatory variables was 


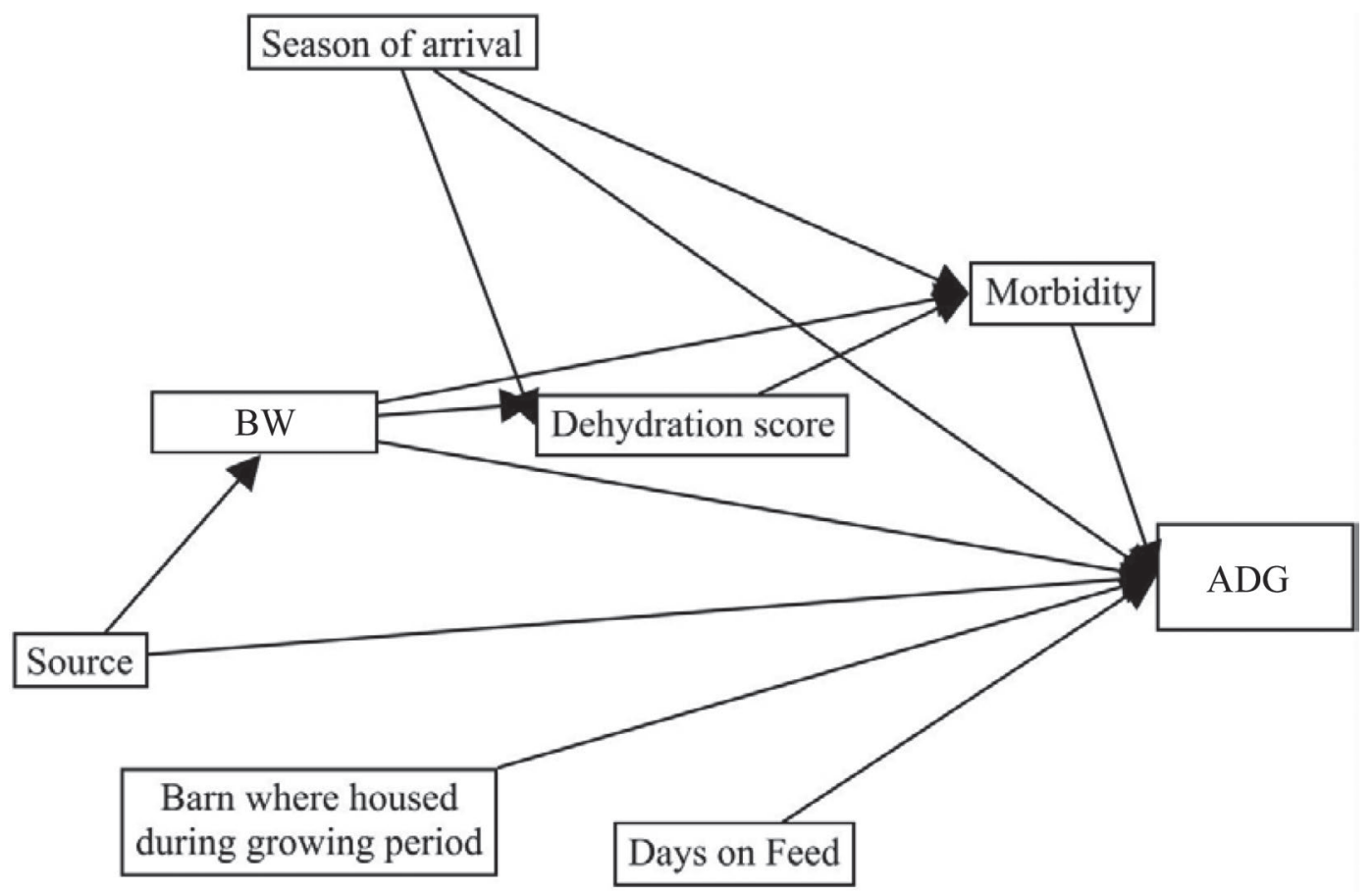

Figure 1. Causal diagram describing the relationship of measured variables to growth performance at a milk-fed veal calf facility in Ontario.

tested using Spearman rank coefficients. If the correlation coefficient between 2 variables was $\geq 0.7$, only one variable was retained based on fewest missing values, reliability of measurement, and biological plausibility. A random effect controlled for the different slaughter plants where the HCW data were collected. Univariable regression models were constructed to screen for variables that were unconditionally associated with the outcome using a liberal $P$-value of 0.2 . Factors potentially associated with ADG were subsequently offered to a multivariable model through a manual backward stepwise process. Confounding effects were evaluated by examining the effect of the removing variables on the coefficients of the remaining variables. A variable was deemed a confounder if it was not an intervening variable based on the causal diagram and the coefficient of a significant variable in the model changed $\geq 20 \%$. Two-way interactions were evaluated between biologically important variables and remained in the final models if significant ( $P$-value $<0.05$; Dohoo et al., 2010a). Homoscedasticity, normality of the residuals, and BLUP were used to evaluate model fit.

\section{RESULTS}

\section{Descriptive Statistics}

A total of 4,825 calves were evaluated from November 2015 to September 2016. An average of 60 calves were evaluated on each day that scoring was conducted, with a range of 6 to 108 calves scored per day. Due to exclusion of inconsistent $\mathrm{HCW}$ data from slaughter plant 4 and 357 calves dying during the production period, 2,283 calves were used for analysis. A total of 359 (16\%), 465 (20\%), 797 (35\%), 333 (15\%), and 329 (14\%) calves were housed in barns $1,2,3,4$, and 5 , respectively. Most calves arrived in the summer (36\%) with the fewest arriving in the fall (13\%); $28 \%$ arrived in the spring and $23 \%$ in the winter. The majority of the calves $(70 \%)$ were drover-derived. Drovers $1,2,3$, 4 , and 5 were responsible for bringing $38,19,2,9$, and $4 \%$ of the calves evaluated. The remaining calves were delivered directly by local farmers $(18 \%)$ or purchased from auction markets (12\%). Most of the calves were male $(98 \%)$ and because the ADG was not statistically different by sex when using a $t$-test $(P=0.30)$, females were retained in the analysis. The age of the calves was not available because Canada does not have an accessible traceability system.

The mean arrival weight of calves was $47 \mathrm{~kg}$ (SD: 5 $\mathrm{kg}$ ) with a range of 28 to $69 \mathrm{~kg}$. The average number of days on feed was $148 \mathrm{~d}$ (SD: $9 \mathrm{~d}$ ) with a range of 119 to $226 \mathrm{~d}$. The calves had an average HCW of $276 \mathrm{~kg}$ (SD: $40 \mathrm{~kg}$ ) and went to 3 slaughter plants. Slaughter plant 2 processed the majority of calves $(62 \%)$. Slaughter plants 1 and 3 processed 13 and $25 \%$ of calves, respectively. Calves gained, on average, $1.13 \mathrm{~kg} / \mathrm{d}$ (SD: $0.21 \mathrm{~kg}$ ) with a range of 0.28 to $1.82 \mathrm{~kg} / \mathrm{d}$. 


\section{Health Parameters}

Table 1 describes the health status of calves on arrival at the veal facility. Very few calves arrived with signs of respiratory disease or joint inflammation. Many calves arrived with some level of clinical dehydration and low BCS. Approximately 13\% of calves arrived with diarrhea (score of 2 or 3 ) and $25 \%$ arrived with an abnormal navel score (score of 2 or 3 ). The mean rectal temperature at arrival was $39^{\circ} \mathrm{C}\left(\mathrm{SD}: 0.8^{\circ} \mathrm{C}\right)$. There were no statistical differences found in the prevalence of health abnormalities measured at arrival when comparing calves sent to the excluded slaughter plant and those retained in the analysis. However, calves retained in the analysis had a greater weight at arrival $(47.2 \mathrm{~kg})$ than the excluded calves $(46.9 \mathrm{~kg})(P=0.04)$.

Table 1. Description and prevalence of risk factors scored on 2,283 calves on arrival at a milk-fed veal facility

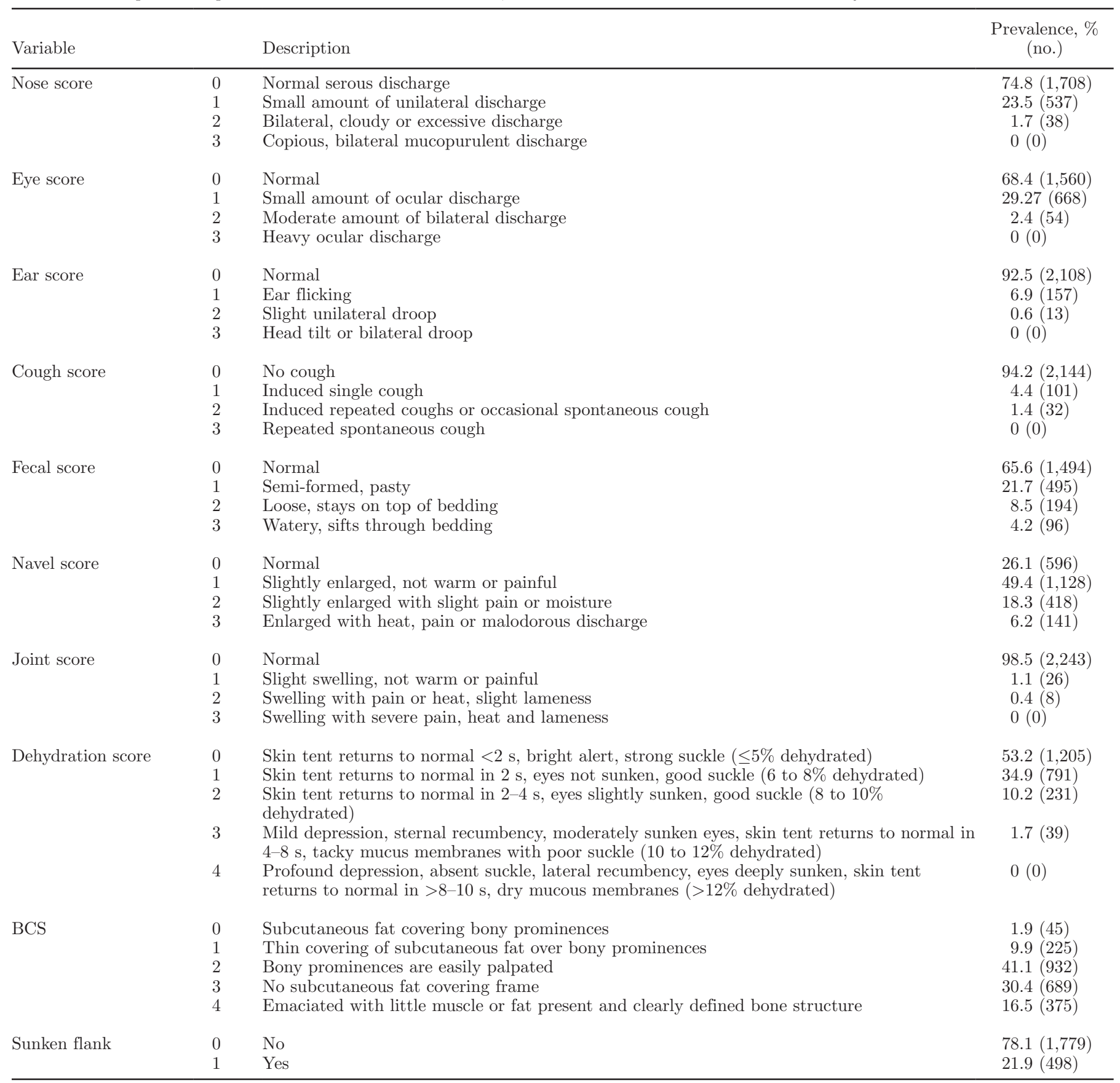




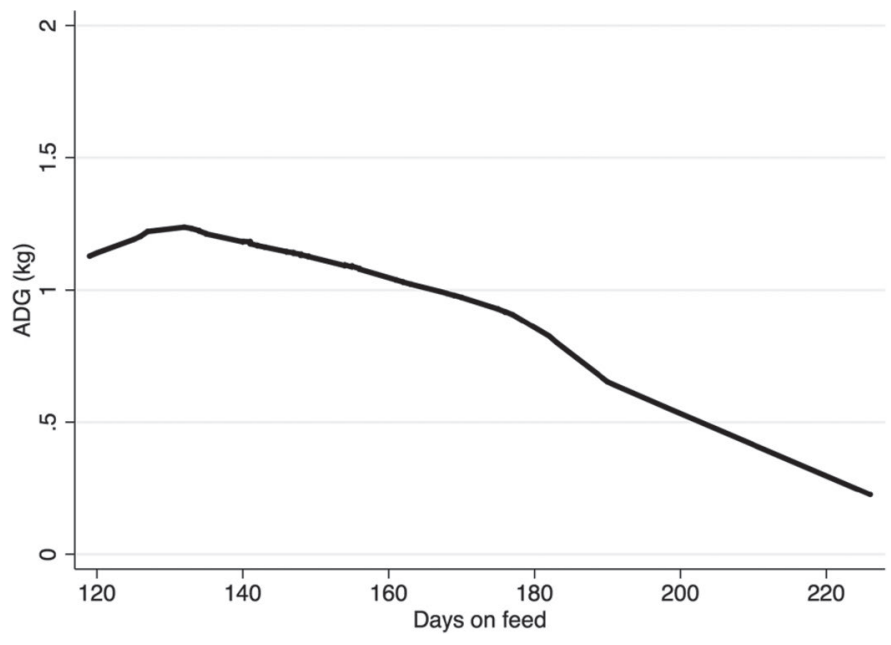

Figure 2. Relationship between the ADG of calves and the number of days the calves were on feed ( $\mathrm{n}=2,283$ calves).

\section{ADG Model}

The variables that were unconditionally associated with ADG were barn, source, season, dehydration score, weight at arrival, days on feed, BCS at arrival, and sex of the calf. No collinearity was found between these variables.

In the final multivariable model, 7 variables were retained (Table 2). Being housed in barns 3, 4, or 5, being sourced from drover 2 , drover 4 , or auction, and having a higher BW at arrival were associated with a higher ADG. Being bought in the summer or fall (compared with winter or spring), and having a dehydration score of 1 or 3 were associated with a lower ADG. Days on feed had a quadratic relationship with ADG (Figure 2). The variance partition coefficient was 0.19 , indicating that $19 \%$ of the variance in ADG can be attributed to difference between how the slaughter plants calculated $\mathrm{HCW}$.

\section{DISCUSSION}

This is the first study to demonstrate that BW and the level of dehydration measured on arrival at a milkfed veal facility are associated with the growth of calves. It also identifies that the source of the calves, housing location, season at arrival, and the number of days spent on feed are associated with the calves' growth. Despite the associations found with ADG, the magni-

Table 2. Results from a multivariable mixed linear regression model evaluating the effect of health status at arrival to a milk-fed veal facility on ADG ( $\mathrm{n}=2,283$ calves)

\begin{tabular}{|c|c|c|c|c|c|}
\hline Variable & Description & $\mathrm{n}$ & Coefficient $(\mathrm{kg} / \mathrm{d})$ & SE & $P$-value \\
\hline Season & $\begin{array}{l}\text { Winter } \\
\text { Spring } \\
\text { Summer } \\
\text { Fall }\end{array}$ & $\begin{array}{l}532 \\
631 \\
828 \\
292\end{array}$ & $\begin{array}{c}\text { Referent } \\
-0.02 \\
-0.07 \\
-0.06\end{array}$ & $\begin{array}{l}0.01 \\
0.01 \\
0.01\end{array}$ & $\begin{array}{r}0.09 \\
<0.01 \\
<0.01\end{array}$ \\
\hline Dehydration score & $\begin{array}{l}0 \\
1 \\
2 \\
3\end{array}$ & $\begin{array}{r}1,205 \\
791 \\
231 \\
39\end{array}$ & $\begin{array}{c}\text { Referent } \\
-0.02 \\
-0.01 \\
-0.08\end{array}$ & $\begin{array}{l}0.01 \\
0.01 \\
0.03\end{array}$ & $\begin{array}{l}0.02 \\
0.50 \\
0.01\end{array}$ \\
\hline Weight at arrival & Per 1-kg increase & & 0.002 & 0.00 & 0.04 \\
\hline $\begin{array}{l}\text { Number of days on feed } \\
\text { Number of days on feed squared }\end{array}$ & Per 1-d increase & & $\begin{array}{c}0.03 \\
-0.0001\end{array}$ & $\begin{array}{l}0.01 \\
0.00\end{array}$ & $\begin{array}{l}<0.01 \\
<0.01\end{array}$ \\
\hline Intercept & & & -0.93 & 0.52 & 0.08 \\
\hline
\end{tabular}


tude of these associations was small, suggesting that other unmeasured factors are affecting growth at the veal facility. A limitation of this study is that the dressing percentage used to calculate live weight was derived from previous data collected at the veal facility. However, the dressing percentage was comparable to other available literature for veal cattle, where it ranged from 59 to 60\% (Andrighetto et al., 1999; Cozzi et al., 2002; Xiccato et al., 2002). Another limitation that should be considered is the number of calves that were lost due to the incomplete records provided by one of the slaughter plants. Selection bias may have resulted from this loss to follow-up; however, the similarities of the excluded and included animals with respect to the prevalence of health abnormalities at arrival suggest that this bias could be minimal (Dohoo et al., 2010b). The nature of the scoring system used is another possible limitation. Renaud et al. (2018) validated the scoring system used, reported the intra- and inter-observer reliability, and demonstrated its ability to identify health abnormalities at arrival that were associated with an increased risk of mortality. Morbidity data were inconsistently reported at these facilities, and is likely is an intervening variable for many of the health parameters measured at arrival (Figure 1); therefore, it was not used in the analysis (Dohoo et al., 2010c).

Certain levels of dehydration were associated with growth. Specifically, dehydration scores of 1 and 3 were associated with reduced growth, whereas a calf with a dehydration score of 2 did not have a significant reduction in growth. This lack of effect could be due to the lower number of calves that were compared with the referent and the smaller magnitude of effect that could be expected when compared with a higher dehydration level. Nonetheless, what remains unclear from this project is whether dehydrated calves with scores of 1 and 3 are at a greater risk of developing a disease that impairs growth (Pardon et al., 2013) or whether they had reduced growth despite remaining clinically healthy. As the level of dehydration was associated with mortality (Renaud et al., 2018), the former may be true. Long transport has been shown to cause dehydration in young calves (Mormede et al., 1982; Knowles et al., 1997) and as calves are not provided with water during transit, transportation may be responsible for the high prevalence of dehydration (Pempek et al., 2017). Some degree of dehydration can be alleviated by providing electrolytes during transit, but the benefits are minor and this strategy may not be practical to implement in a commercial setting (Knowles et al., 1999). Dehydration occurring before transport from the dairy farm of origin may also explain the high prevalence of dehydration. Thus, provision of oral fluids before departure from the dairy farm of origin could be a practical strategy to consider, where the fluids could alleviate any dehydration present before departure and mitigate the losses of fluids that may occur during transit. As dehydration is a common finding in calves arriving at veal facilities (Wilson et al., 2000; Pempek et al., 2017), more research is necessary to identify reasons for its high prevalence and strategies to reduce its impact on mortality and growth.

Body weight was associated with growth, where calves with a greater BW at arrival had a higher ADG than those with a lower BW. Body weight at arrival has also been associated with mortality and morbidity in veal calves (Brscic et al., 2012; Winder et al., 2016), suggesting that it is an important variable that influences the success of the calves. As BW at arrival is a function of age and previous nutrition (Winder et al., 2016), these factors should be explored as a mechanism to improve the growth, health, and welfare of the arriving calves.

Season of birth has been previously shown to influence the growth of female dairy calves (Donovan et al., 1998; Windeyer et al., 2014). An interesting finding in this study was that calves had better performance in the winter months. Cold stress can result in more energy being diverted to heat production, leading to a reduced rate of gain (Roland et al., 2016), but these barns were heated during the winter. The summer of 2015 was unseasonably hot and humid in Ontario (Seglenieks, 2016) and heat stress could have resulted, leading to impaired immune function (Roland et al., 2016), increasing the risk of pneumonia and compromising growth (Stanton et al., 2012). As heat dissipation strategies are not used at this facility, the reasons stated above may have been responsible for the reduction in growth during the summer.

Source of the calves had an influence on the growth of calves. Colostrum management and plane of nutrition are critical components of early life management on source dairy farms that influence the health and productivity of calves (Faber et al., 2005; Windeyer et al., 2014; Todd et al., 2017). As the management of these factors vary depending on the source dairy farm of origin (Renaud et al., 2017), this could explain some of the variation present with regard to the different sources. A counterintuitive finding was that calves from local dairy farms had a lower ADG than calves from many of the other sources. The practice of the veal facility was such that local dairy producers bringing calves to this facility were less likely than drovers to be penalized (i.e., paid a lower price) for lightweight or sick calves. We speculate that drovers screened the calves that they purchased at source dairy farms such 
that calves that were ill or of low weight were not taken from the source farm.

Days on feed had a quadratic relationship with the growth of the calves. The ADG of the calves increased to $130 \mathrm{~d}$ on feed and began to decline thereafter, suggesting that there is an optimal threshold for shipping calves to slaughter. As calves are still consuming high volumes of milk replacer in the latter stages of the production cycle, this reduction in ADG would likely affect feed efficiency.

\section{CONCLUSIONS}

Based on the results of this study, the level of dehydration and BW measured at arrival are associated with the ADG of calves. However, as the effect of the measured parameters on ADG was relatively small, other factors may be responsible for changes in growth performance.

\section{ACKNOWLEDGMENTS}

The authors thank the participating producer. The first author was supported by Grober Inc. (Cambridge, ON, Canada), Veal Farmers of Ontario (Guelph, ON, Canada), Dairy Farmers of Ontario (Mississauga, ON, Canada), the Ontario Ministry of Agriculture, Food, and Rural Affairs, and the Ontario Veterinary College (University of Guelph).

\section{REFERENCES}

Agriculture and Agri-Food Canada. 2016. Veal supply at a glance - Canada. Accessed Jul. 27, 2018. http://ontarioveal.on.ca/wp -content/uploads/2014/04/Sept03V-english.pdf.

Andrighetto, I., F. Gottardo, D. Andreoli, and G. Cozzi. 1999. Effect of housing on veal calf growth performance, behaviour and meat quality. Livest. Prod. Sci. 57:137-145.

Bähler, C., A. Steiner, A. Luginbühl, A. Ewy, H. Posthaus, D. Strabel, T. Kaufmann, and G. Regula. 2012. Risk factors for death and unwanted early slaughter in Swiss veal calves kept at a specific animal welfare standard. Res. Vet. Sci. 92:162-168. https://doi .org/10.1016/j.rvsc.2010.10.009.

Brscic, M., H. Leruste, L. Heutinck, E. Bokkers, M. Wolthuis-Fillerup, N. Stockhofe, F. Gottardo, B. Lensink, G. Cozzi, and C. V. Reenen. 2012. Prevalence of respiratory disorders in veal calves and potential risk factors. J. Dairy Sci. 95:2753-2764. https://doi.org/ 10.3168/jds.2011-4699.

Cozzi, G., F. Gottardo, S. Mattiello, E. Canali, E. Scanziani, M. Verga, and I. Andrighetto. 2002. The provision of solid feeds to veal calves: I. Growth performance, forestomach development, and carcass and meat quality. J. Anim. Sci. 80:357-366.

De Vries, A., M. Overton, J. Fetrow, K. Leslie, S. Eicker, and G. Rogers. 2008. Exploring the impact of sexed semen on the structure of the dairy industry. J. Dairy Sci. 91:847-856. https://doi.org/10 $.3168 /$ jds.2007-0536.

Dohoo, I., W. Martin, and H. Stryhn. 2010a. Model-Building Strategies. Pages 365-394 in Veterinary Epidemiological Research. 2nd ed. VER Inc., Charlottetown, Prince Edward Island, Canada.
Dohoo, I., W. Martin, and H. Stryhn. 2010b. Validity in observational studies. Pages 243-270 in Veterinary Epidemiological Research. 2nd ed. VER Inc., Charlottetown, Prince Edward Island, Canada.

Dohoo, I., W. Martin, and H. Stryhn. 2010c. Confounding: Detection and control. Pages 271-322 in Veterinary Epidemiological Research. 2nd ed. VER Inc., Charlottetown, Prince Edward Island, Canada.

Donovan, G. A., I. R. Dohoo, D. M. Montgomery, and F. L. Bennett. 1998. Calf and disease factors affecting growth in female Holstein calves in Florida, USA. Prev. Vet. Med. 33:1-10.

Faber, S., N. Faber, T. Mccauley, and R. Ax. 2005. Case study: Effects of colostrum ingestion on lactational performance. Prof. Anim. Sci. 21:420-425. https://doi.org/10.15232/s1080-7446(15)31240-7.

Fecteau, G., J. Pare, D. Van Metre, B. Smith, C. Holmberg, W. Guterbock, and S. Jang. 1997. Use of a clinical sepsis score for predicting bacteremia in neonatal dairy calves on a calf rearing farm. Can. Vet. J. 38:101-104.

Knowles, T. G., G. Brown, J. Edwards, A. Phillips, and P. Warriss. 1999. Effect on young calves of a one-hour feeding stop during a 19-hour road journey. Vet. Rec. 144:687-692. https://doi.org/10 $.1136 /$ vr.144.25.687.

Knowles, T. G., G. Warriss, S. Brown, J. Edwards, P. Watkins, and A. Phillips. 1997. Effects on calves less than one month old of feeding or not feeding them during road transport of up to 24 hours. Vet. Rec. 140:116-124.

McGuirk, S. M. 2008. Disease management of dairy calves and heifers. Vet. Clin. North Am. Food Anim. 24:139-153. https://doi.org/10 .1016/j.cvfa.2007.10.003.

McGuirk, S. M., and S. Peek. 2014. Timely diagnosis of dairy calf respiratory disease using a standardized scoring system. Anim. Health Res. Rev. 15:145-147. https://doi.org/10.1017/ S1466252314000267.

Mormede, P., J. Soissons, R. M. Bluthe, J. Raoult, G. Legarff, D. Levieux, R. Dantzer, J. F. Chaillou, M. C. Geffard, and D. Arnoux. 1982. Effect of transportation on blood serum composition, disease incidence, and production traits in young calves. Influence of the journey duration. Ann. Rech. Vet. 13:369-384.

Pardon, B., M. Hostens, L. Duchateau, J. Dewulf, K. D. Bleecker, and P. Deprez. 2013. Impact of respiratory disease, diarrhea, otitis and arthritis on mortality and carcass traits in white veal calves. BMC Vet. Res. 9:79. https://doi.org/10.1186/1746-6148-9-79.

Pempek, J., D. Trearchis, M. Masterson, G. Habing, and K. Proudfoot. 2017. Veal calf health on the day of arrival at growers in Ohio. J. Anim. Sci. 95:3863-3872. https://doi.org/10.2527/jas2017 1642 .

Pigott, T. D. 2001. A review of methods for missing data. Educ. Res. Eval. 7:353-383. https://doi.org/10.1076/edre.7.4.353.8937.

Renaud, D. L., T. Duffield, S. LeBlanc, S. Ferguson, D. Haley, and D. Kelton. 2018. Risk factors associated with mortality at a milkfed veal calf facility: A prospective cohort study. J. Dairy Sci. 101:2659-2668. https://doi.org/10.3168/jds.2017-13581.

Renaud, D. L., T. F. Duffield, S. J. LeBlanc, D. B. Haley, and D. F. Kelton. 2017. Management practices for male calves on Canadian dairy farms. J. Dairy Sci. 100:6862-6871.

Roland, L., M. Drillich, D. Klein-Jöbstl, and M. Iwersen. 2016. Invited review: Influence of climatic conditions on the development, performance, and health of calves. J. Dairy Sci. 99:2438-2452. https: //doi.org/10.3168/jds.2015-9901.

Seglenieks, F. 2016. University of Waterloo weather station annual summary, 2016. Assessed Mar. 26, 2017. http://weather.uwaterloo .ca/download/historical/2016/UW_weather_station_summary 2016.pdf.

Stanton, A. L., D. Kelton, S. Leblanc, J. Wormuth, and K. Leslie. 2012. The effect of respiratory disease and a preventative antibiotic treatment on growth, survival, age at first calving, and milk production of dairy heifers. J. Dairy Sci. 95:4950-4960. https://doi .org/10.3168/jds.2011-5067.

Todd, C., K. Leslie, S. Millman, V. Bielmann, N. Anderson, J. Sargeant, and T. Devries. 2017. Clinical trial on the effects of a free-access acidified milk replacer feeding program on the health 
and growth of dairy replacement heifers and veal calves. J. Dairy Sci. 100:713-725. https://doi.org/10.3168/jds.2016-11401.

Virtala, A.-M., G. Mechor, Y. Gröhn, and H. Erb. 1996. The effect of calfhood diseases on growth of female dairy calves during the first 3 months of life in New York State. J. Dairy Sci. 79:1040-1049. https://doi.org/10.3168/jds.S0022-0302(96)76457-3.

Wilson, L. L., J. Smith, D. Smith, D. Swanson, T. Drake, D. Wolfgang, and E. Wheeler. 2000. Characteristics of veal calves upon arrival, at 28 and 84 days, and at end of the production cycle. J. Dairy Sci. 83:843-854. https://doi.org/10.3168/jds.S0022-0302(00)74948-4.

Winder, C. B., D. Kelton, and T. Duffield. 2016. Mortality risk factors for calves entering a multi-location white veal farm in Ontario,
Canada. J. Dairy Sci. 99:10174-10181. https://doi.org/10.3168/ jds.2016-11345.

Windeyer, M. C., K. Leslie, S. Godden, D. Hodgins, K. Lissemore, and S. Leblanc. 2014. Factors associated with morbidity, mortality, and growth of dairy heifer calves up to 3 months of age. Prev. Vet. Med. 113:231-240. https://doi.org/10.1016/j.prevetmed.2013 .10.019.

Xiccato, G., A. Trocino, P. I. Queaque, A. Sartoli, and A. Carazzolo. 2002. Rearing veal calves with respect to animal welfare: Effects of group housing and solid feed supplementation on growth performance and meat quality. Livest. Prod. Sci. 75:269-280. 